ARTIGO

\title{
DESENVOLVIMENTO DE ALGORITMO PARA ACIONAMENTO INTELIGENTE DE FARÓIS AUTOMOTIVOS ${ }^{1}$
}

\author{
Andrey Gustavo de Souza ${ }^{2}$ \\ Gustavo Lobato Campos
}

\section{RESUMO}

A Lei 13.290/2016 tornou obrigatório o uso do farol baixo do veículo em rodovias durante o dia com o objetivo de reduzir o número de acidentes, principalmente considerando a colisão frontal em estradas de mão dupla e acidentes envolvendo pedestres e ciclistas. Diversos países europeus, além do Canadá e alguns estados norte-americanos já adotam medida semelhante. Diante de tal cenário, surge uma nova demanda na indústria automotiva, um sistema que acione o farol se o veículo estiver trafegando em rodovias e o desligue em caso deste trafegar em vias urbanas, de forma automática e inteligente. Assim, a proposta deste trabalho é a implantação de um sistema inteligente, em escala reduzida, para o acionamento dos faróis do veículo quando o mesmo trafegar em rodovias. Destaca-se que o sistema proposto utiliza informações já presentes no veículo, ou seja, sem necessidade de maiores investimentos por parte das montadoras. Um estudo das características peculiares a cada meio (rodovias e vias urbanas) será realizado, bem como o levantamento de quais variáveis são utilizadas com o objetivo de determinar se o veículo trafega por uma rodovia ou não, por meio de análises estatísticas.

Palavras-chave: Sistemas automotivos. Eletrônica automotiva. Sistemas embarcados.

\section{INTRODUÇÃO}

A eletrônica embarcada em veículos é amplamente empregada e proporcionou uma revolução no setor automotivo. De tal modo, tecnologias hoje presentes em praticamente todos os modelos de carros, motos e outros veículos só foram possíveis quando o uso de centrais eletrônicas de processamento (ECU) passou a ser empregado. Funções como freios ABS, injeção eletrônica, airbags, entre outros, são imprescindíveis para o funcionamento eficiente do veículo, bem como garantem níveis de segurança superiores aos vistos no advento do emprego das ECU's.

\footnotetext{
${ }^{1}$ Como citar este artigo: SOUZA, Andrey Gustavo de; CAMPOS, Gustavo Lobato. Desenvolvimento de algoritmo para acionamento inteligente de faróis automotivos. ForScience: revista científica do IFMG, Formiga, v. 6, n. 1, e00224, jan./jul. 2018.
}

${ }^{2}$ Autor para correspondência: Andrey Gustavo de Souza, UFLA, e-mail: andrey.souza@posgrad.ufla.br 
Dentre várias aplicações dos sistemas embarcados em automóveis, destaca-se a automatização de funções do veículo, dentre as quais podemos destacar:

- Uso de sensores crepusculares ou de luminosidade que automatizaram o acionamento de faróis em situação onde a luminosidade é baixa, como em túneis, nevoeiros e quando o veículo trafega à noite;

- Sensor de chuva, que aciona o limpador de tal forma que a visibilidade do condutor não seja prejudicada, caso o veículo esteja trafegando sob chuva;

- Desligamento automático da seta, que desliga a seta automaticamente, caso o veículo tenha concluído a conversão,

Além de automatizar algumas funções, os fabricantes de automóveis sempre estão atentos às mudanças de legislação, que muitas vezes fazem com que algumas funções antes tidas como opcionais se tornem obrigatórias. Como exemplo, podem ser destacadas as resoluções no 311 e no 312 do Conselho Nacional de Trânsito (Contran) que, respectivamente, obrigam as montadoras a comercializarem veículos com airbag e freios ABS como itens de série (MENDES, 2009).

Com o passar dos anos, as leis que regem o trânsito brasileiro sofreram várias mudanças, a fim de se preservar a segurança dos motoristas, passageiros e pedestres. Destacase que a legislação brasileira é vasta, rica em leis, resoluções e portarias que foram publicadas no decorrer dos 116 anos passados de sua criação, citando ainda suas constantes revisões e atualizações.

O Brasil ao longo do tempo nunca deu a devida atenção à segurança no trânsito, que apresenta um alarmante número anual de mortos e feridos, quando comparado a vários outros países. Contudo, nunca esteve em pauta a criação de um órgão específico que controlasse o trânsito e que se preocupasse em diminuir o número de vítimas. $\mathrm{O}$ fato marcante nesse meio tempo foi a criação do Código De Trânsito Brasileiro em 1998, que trouxe consigo novas leis e normas que acarretariam em multas aos condutores infratores, resultando em uma diminuição no número de fatalidades (FRANZ; VIEIRA, 2012).

Uma dessas leis, instaurada mais recentemente, a Lei 13.290/2016, determina o uso obrigatório de farol baixo durante o dia em rodovias e altera o Código de Trânsito Brasileiro nesse aspecto. A medida tem por objetivo aumentar a segurança nas estradas, uma vez que a baixa visibilidade é umas das principais causas de acidentes hoje no Brasil. Apesar do Contran já ter editado uma resolução em 1998 recomendando o uso de farol baixo nas 
rodovias durante o dia, o entendimento é de que apenas uma norma com força de lei levaria os motoristas a adotarem a medida.

As montadoras, atentas a essa lei e ao nicho de mercado que ela criou, já estudam a criação de um sistema inteligente que automatize o acionamento de faróis em rodovias, com o objetivo de evitar que o condutor seja penalizado por não estar com o farol aceso por desatenção. Esse sistema, além de ser útil ao condutor, também poderá servir em ações de marketing, uma vez que este recurso seria uma novidade no competitivo mercado automotivo. Destaca-se que se deve buscar um sistema não complexo, para que o mesmo possa ser aplicado a todos os modelos de veículos produzidos, e não somente àqueles de alto valor, conhecidos no segmento por "high line".

\section{REFERENCIAL TEÓRICO}

\subsection{Estado da Arte}

Em países europeus, o Canadá e alguns estados norte-americanos, os veículos já saem de fábrica com um sistema chamado Daytime Running Light (DRL), ou luzes de circulação diurna que se trata de um dispositivo de iluminação diurna que liga automaticamente com o carro. A legislação europeia adotou a obrigatoriedade do sistema em 2008 para todos os tipos de carros de passageiros e a partir de fevereiro de 2011 para vans. Caminhões e ônibus passaram a contar com o dispositivo de forma obrigatória em agosto de 2012 (THE AA, 2014).

Com relação à legislação brasileira, não há na literatura e nem mesmo no portfólio de funcionalidades das montadoras um sistema inteligente que cumpra a tarefa de acionar o farol automaticamente em caso de o mesmo trafegar em uma rodovia ou fazer seu desligamento em caso de o veículo trafegar por um trecho urbano. Apenas existe o sistema de sensor crepuscular que faz esse acionamento em caso de baixa luminosidade.

\section{DESENVOLVIMENTO}

\subsection{Cenários analisados}

A carência de dados e estudos disponíveis relacionados aos padrões de variáveis do veículo em diferentes tipos de ambientes (urbano e rodovias) fez com que se definisse para 
estudo neste trabalho trechos de diferentes tipos de rodovias a fim de se extrapolar dados como, de velocidade média, ângulo de volante e rotações por minuto do motor, necessários para se realizar a atividade proposta.

Os dados foram extraídos de informações provenientes do Google Maps, que fornece algumas informações sobre os trechos analisados tais como, tempo de viagem esperado e distância entre os locais. Os três cenários estudados são apresentados e descritos resumidamente a seguir:

a) Trecho viário 1: Formiga, MG a Divinópolis, MG: Trecho localizado na região do centro-oeste de Minas Gerais, pertencente à rodovia MG-050, que liga a região metropolitana de Belo Horizonte à região sudoeste do estado, terminando na cidade de São Sebastião do Paraíso. O percurso é caracterizado por ser de pista simples, em trecho acidentado e sinuoso. O trajeto, mostrado na Figura 1, que compreende o trecho entre as cidades de Divinópolis e Formiga, a distância é de 72,8 km, com tempo médio de viagem de 53 minutos, logo a velocidade média será dada pela Equação (1).

$$
V_{\text {med }}=\frac{\Delta d}{\Delta t}=\frac{72,8}{53 / 60}=82,4 \mathrm{~km} / \mathrm{h}
$$

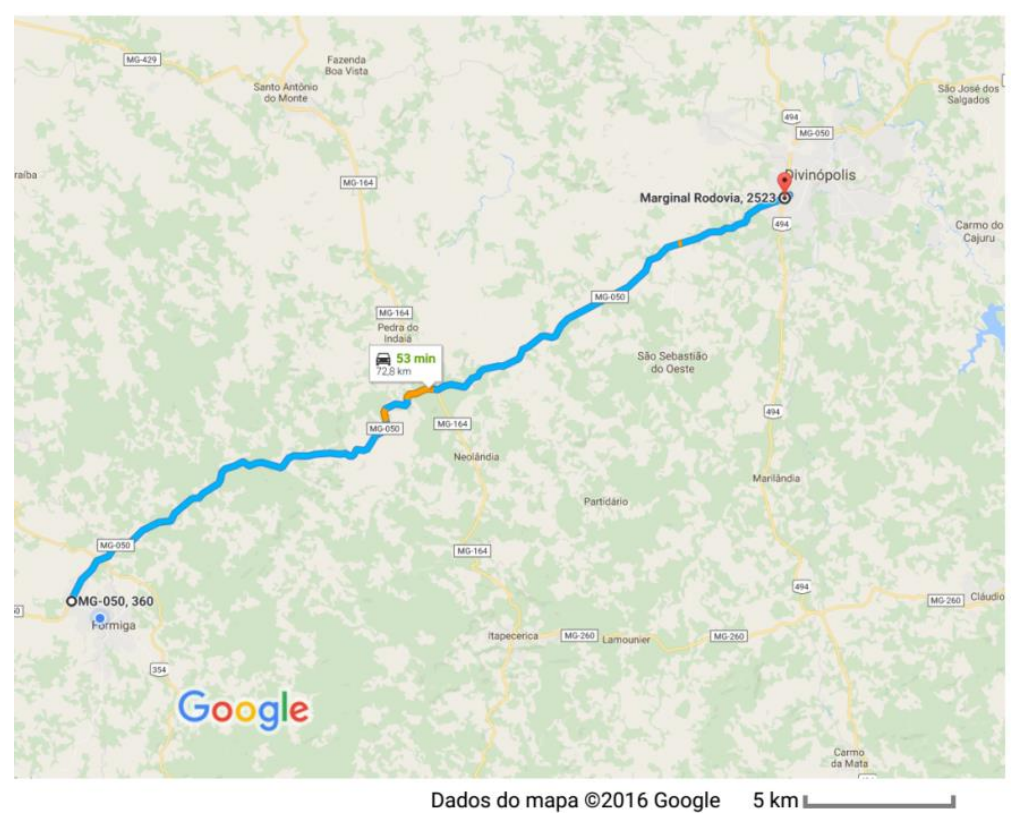

Figura 1- Trecho viário 1: Formiga - Divinópolis Fonte: Google Maps (2016). 
b) Trecho viário 2: Trevo de Oliveira, MG ao Trevo de Três Corações, MG: Trecho viário localizado na rodovia federal Fernão Dias, BR-381, que liga Belo Horizonte, MG a São Paulo, SP. Esse percurso é caracterizado por ser de pista duplicada, porém em trecho acidentado e sinuoso. Os dados do Google Maps, como mostrado na Figura 2, mostram que a distância entre os dois pontos, especificamente entre os trevos das cidades de Oliveira e Três Corações, é de 134 km e é realizada por um carro em tempo médio de 1 hora e 25 minutos, logo a velocidade média é dada pela Equação (2).

$$
V_{\text {med }}=\frac{\Delta d}{\Delta t}=\frac{134}{1+25 / 60}=94,6 \mathrm{~km} / \mathrm{h}
$$

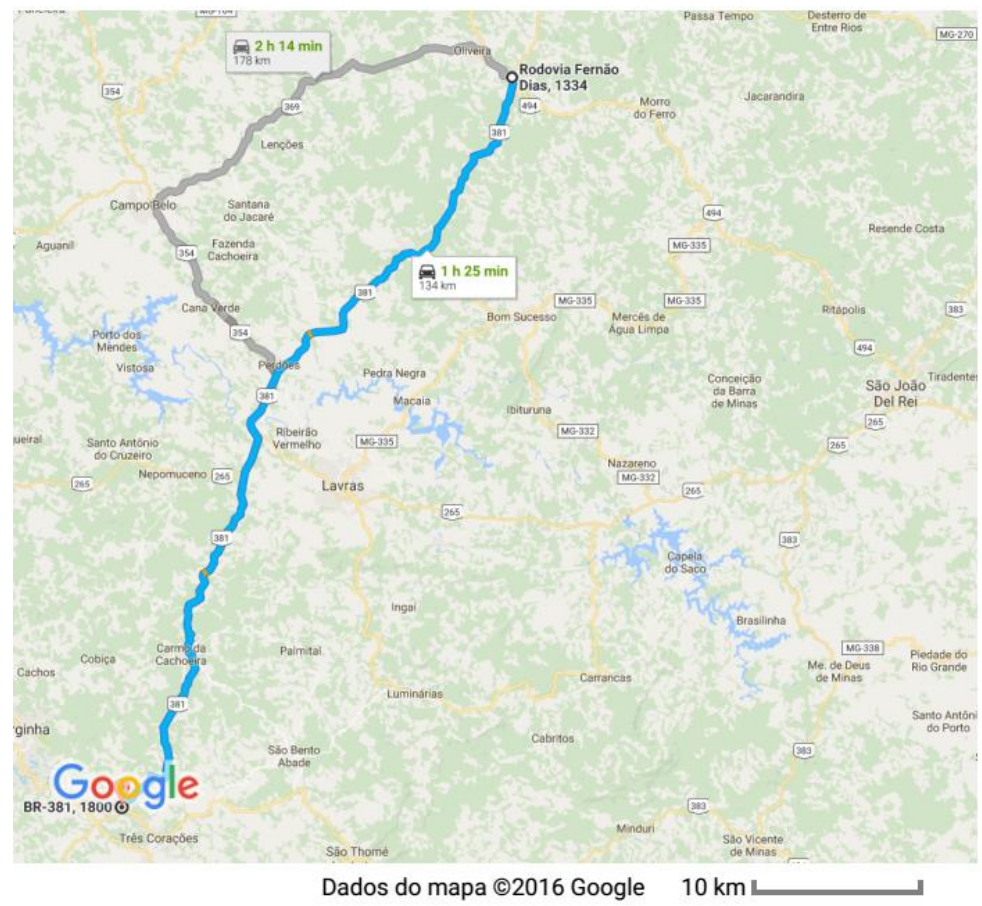

Figura 2 - Trecho viário 2: Oliveira - Três Corações Fonte: Google Maps (2016).

c) Trecho viário 3: Araraquara, SP a São José do Rio Preto, SP: Trecho viário analisado é parte da rodovia Washington Luís, SP-310. Trata-se de uma rodovia radial e faz a ligação de São Paulo aos municípios de Rio Claro, São Carlos, Araraquara, Catanduva e São José do Rio Preto, dentre outros. O trecho analisado, entre as cidades de Araraquara e São José do Rio Preto, tem pista duplicada e sem muitas curvas e aclives/declives. De acordo com os dados do Google Maps, o trecho analisado, como 
mostrado pela Figura 3, tem distância de 165 km e é percorrido em tempo médio de 1 hora e 40 minutos, logo a velocidade média é dada pela Equação (3).

$$
V_{\text {med }}=\frac{\Delta d}{\Delta t}=\frac{165}{1+40 / 60}=99 \mathrm{~km} / \mathrm{h}
$$

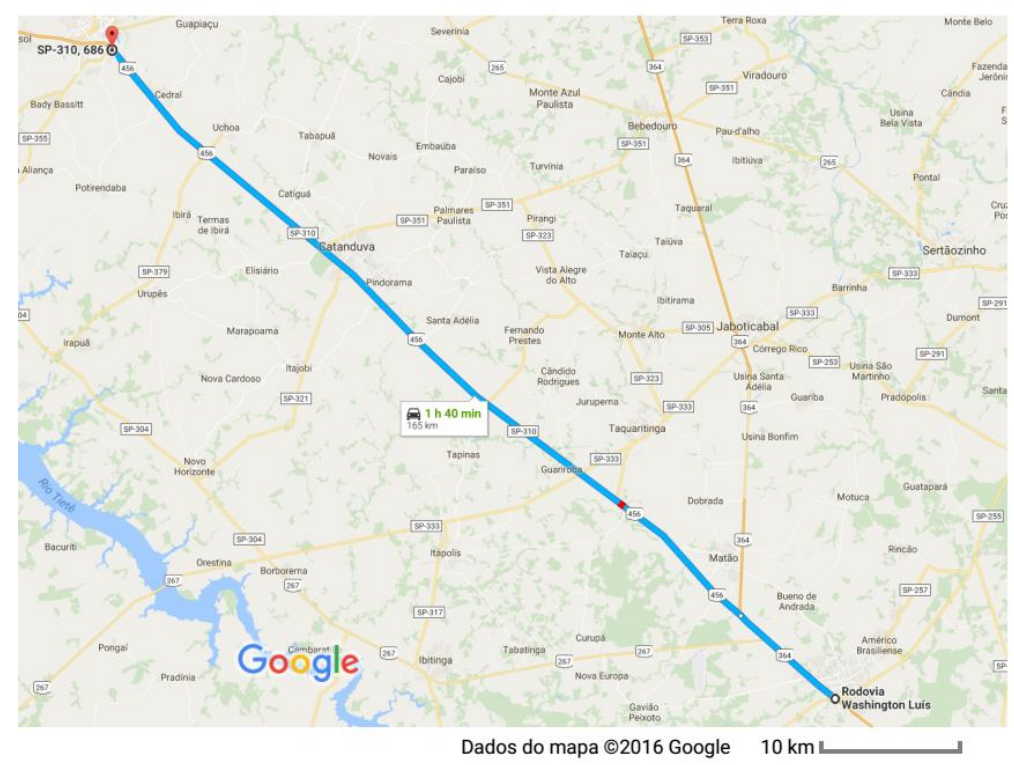

Figura 3- Trecho viário 3: Araraquara - S. J. do Rio Preto Fonte: Google Maps (2016).

\subsection{Escolha de variáveis}

Durante a fase de planejamento do projeto, foram levantadas diversas variáveis presentes no barramento de comunicação da maioria dos automóveis. Em uma análise primária foram selecionadas as seguintes variáveis:

- Velocidade.

- Rotações por minuto do motor.

- Angulação do volante.

- Sensor de luminosidade.

- Marcha.

- Posição do acelerador.

Após uma análise estatística das variáveis medidas, constatou-se que algumas delas não são relevantes à proposta deste trabalho. A primeira a ser descartada foi a posição do 
acelerador, por muitas vezes o condutor não está pisando no acelerador, por estar com o pé acionando os freios, ou por qualquer outro motivo. Outra variável que não faz parte do sistema desenvolvido é o sensor de marcha, que é proporcional à rotação do motor e à velocidade em que o veículo se encontra, podendo assim ser desconsiderado neste momento. Contudo para a função gatilho, essa variável se torna útil, portanto, não é descartada totalmente do sistema.

Já o sensor de luminosidade é um sensor prioritário, ou seja, se a luminosidade estiver em níveis abaixo do aceitável, o farol é acionado sem a necessidade de o algoritmo entrar em operação, estando em um nível hierárquico acima da circunstância que o modelo proposto opera.

Dessa forma as variáveis que definem se o farol deve permanecer aceso, de caráter preliminar são:

- Velocidade.

- Rotações por minuto do motor.

- Angulação do volante.

\subsection{Métodos estatísticos aplicados no algoritmo}

Um dos grandes desafios no desenvolvimento do algoritmo foi a ausência de dados reais das variáveis do veículo para assim aplicá-las ao algoritmo elaborado e avaliá-lo em diferentes situações de operação. Ciente disso, partiu-se do princípio de que o veículo em uma rodovia não sofre variações bruscas em nenhuma das variáveis analisadas. Mesmo em pista simples e com trajeto sinuoso e acidentado, as variações são suaves em condições de operação normais.

O que se observa na cidade é uma situação oposta, visto que por muitas vezes o veículo para em cruzamentos, semáforos e travessia de pedestres, isto faz com que a velocidade apresente valores muito próximos a zero, e desta forma o desvio padrão da velocidade, analisado em uma amostragem de tempo, seja superior se comparado ao de uma rodovia. Outro fator que contribui para a diferenciação entre as duas situações é o ângulo do volante, em que diversas conversões de $90^{\circ}$ ou mais são realizadas e em seguida retornam à posição zero. O giro do motor é outra variável que sofre considerável variação na cidade, visto que a cada parada, o condutor sai da primeira marcha, evolui o câmbio para marchas 
mais altas. A cada vez que essa comutação acontece, ocorre uma variação considerável nos níveis de giro do motor, o que não ocorre na estrada, onde raramente o veículo não opera com alto giro motor, ou próximo a este.

Partindo desta hipótese, o coeficiente de variação do vetor de leituras dessas três variáveis do veículo (velocidade, giro do motor e angulação do volante) se torna uma ferramenta importante na identificação e manutenção da condição de rodovia do sistema. De posse dos dados inferidos no item anterior do presente trabalho tem-se os dados de média e desvio padrão das três variáveis analisadas em cada trecho apresentados na Tabela 1.

Tabela 1- Parâmetros obtidos nos cenários estudados

\begin{tabular}{l|c|c|c|c|c|c}
\hline \multirow{2}{*}{ Variável } & \multicolumn{2}{|c|}{ Trecho 1 } & \multicolumn{2}{c|}{ Trecho 2 } & \multicolumn{2}{c}{ Trecho 3 } \\
\cline { 2 - 7 } & Média & Desvio padrão & Média & Desvio padrão & Média & Desvio padrão \\
\hline Velocidade $(\mathrm{km} / \mathrm{h})$ & 72,8 & 9 & 94,6 & 6 & 99 & 4 \\
RPM & 3500 & 500 & 3500 & 300 & 3500 & 300 \\
Ângulo do volante $\left({ }^{\circ}\right)$ & 0 & 20 & 0 & 11 & 0 & 8 \\
\hline
\end{tabular}

Fonte: Elaborado pelo autor.

É importante ressaltar que esses dados são frutos de observações, uma vez que não existem dados disponíveis na literatura e o objetivo do trabalho é um sistema genérico que poderá ser calibrado futuramente por dados reais, ou seja, este trabalho tem por objetivo a apresentação do modelo a ser aplicado.

Com isso, tem-se que na pior hipótese de desvio padrão (DP) (trecho 1) e, por conseguinte, o pior caso do coeficiente de variação. O coeficiente de variação (CV) é usado para analisar a dispersão em termos relativos a seu valor médio quando duas ou mais séries de valores apresentam unidades de medida diferentes. Dessa forma, pode-se dizer que o coeficiente de variação é uma forma de expressar a variabilidade dos dados excluindo a influência da ordem de grandeza da variável, fornecendo medidas de quão heterogêneo são os dados analisados. É importante ressaltar que quanto mais próximo de zero estão os valores, menos representativo é o valor do coeficiente de variação. Por esta razão a medida de dispersão utilizada para mensurar a variabilidade do ângulo do volante é seu desvio padrão. A Tabela 2 apresenta os valores do coeficiente de variação que servirão de parâmetros para calibrar o algoritmo. 
Tabela 2 - Coeficiente de Variação dos trechos analisados

\begin{tabular}{l|l|l|l}
\hline \multirow{2}{*}{ Variável } & \multicolumn{1}{|c|}{ Trecho 1 } & \multicolumn{1}{c}{ Trecho 2 } & \multicolumn{1}{c}{ Trecho 3 } \\
\cline { 2 - 4 } & Coeficiente de Variação & Coeficiente de Variação & Coeficiente de Variação \\
\hline Velocidade $(\mathrm{km} / \mathrm{h})$ & $12,36 \%$ & $6,34 \%$ & $4,04 \%$ \\
RPM & $14,28 \%$ & $8,57 \%$ & $8,57 \%$ \\
\hline
\end{tabular}

Fonte: Elaborado pelo autor.

\subsection{Lógica de acionamento e manutenção da condição de farol aceso}

No momento em que o veículo entra em uma rodovia é necessário que a ação de acionar o farol seja feita de maneira rápida, para tal, foi elaborada a chamada condição gatilho. Sabe-se que o veículo quando entra em uma rodovia, acelera de tal modo a alcançar a velocidade nominal da pista. Até chegar à velocidade desejada, o veículo é acelerado, alcançando um giro relativamente alto. Também, espera-se que não aconteçam variações bruscas na direção do veículo, logo a angulação do volante também não varia bruscamente. Outro ponto observado nessa situação é a progressão de marchas em um curto espaço de tempo.

Partindo das hipóteses mencionadas acima, a Tabela 3 apresenta os valores de gatilho das variáveis monitoradas em tempo real que acionarão o farol de forma automática.

Tabela 3 - Parâmetros de gatilho para acionamento do farol

\begin{tabular}{c|c|c|c}
\hline Velocidade & Rotação do motor & Ângulo do volante & Marcha \\
\hline$>65 \mathrm{~km} / \mathrm{h}$ & $>3500 \mathrm{rmp}$ & Entre $-15^{\circ}$ e $15^{\circ}$ & $\geq 4^{\mathrm{a}}$ \\
\hline
\end{tabular}

Fonte: Elaborado pelo autor.

Depois que o farol já esteja aceso, por meio das condições mencionadas acima, são feitas análises estatísticas das variáveis do veículo de tal modo a preservar ou não a condição de farol aceso. A cada 500ms é feita uma leitura de cada uma das três variáveis (velocidade, giro do motor e angulação do volante) durante um minuto, totalizando assim 120 leituras. Então é realizada análise estatística desse conjunto de medidas de forma a calcular o coeficiente de variação de cada uma das variáveis. Se todos os valores estiverem com variações não condizentes com uma situação de rodovia, o algoritmo estabelece uma situação de alerta. 
Se por quatro vezes seguidas essa situação de alerta é estabelecida, então o sistema emite um alerta ao usuário, comunicando que o farol será desligado a menos que o usuário confirme que ainda deseje que o farol seja mantido acionado. Os valores das medidas em que a situação de alerta é estabelecida, são os valores de coeficiente de variação do trecho 1, pior caso em relação à dispersão de medidas, arredondados para cima, tal como mostrado na Tabela 4.

Tabela 4 - Valores de coeficiente de variação em que a situação de alerta é estabelecida

\begin{tabular}{c|c|c}
\hline Velocidade (CV) & Rotação do motor (CV) & Ângulo do volante (DP) \\
\hline$>13 \%$ & $>15 \%$ & $>20^{\circ}$ \\
\hline
\end{tabular}

Fonte: Elaborado pelo autor.

\section{RESULTADOS E DISCUSSÕES}

\subsection{Implementação do algoritmo}

Para a implementação do algoritmo foi necessária uma análise minuciosa de todas as possibilidades, limitações e ações prioritárias que o sistema deve analisar. Para tal, um sistema hierárquico de prioridades foi elaborado, conforme descrito a seguir:

1. Farol em operação manual: se o usuário decidir acionar o farol de modo manual a qualquer momento, o farol deve ser acionado sem que qualquer outra medida de acionamento seja tomada até que o mesmo seja colocado em operação manual.

2. Farol em operação em baixa luminosidade: se o sensor de luminosidade detectar nível de luminosidade abaixo do aceitável, o farol deve ser acionado sem que o sistema de detecção de estrada entre em operação. Se os níveis de luminosidade estiverem em níveis normais, o farol deve ser desligado e o sistema de detecção de estrada entra em operação imediata.

3. Farol em operação em rodovia: se as leituras de variáveis apontarem que o veículo opera em rodovia, o farol é acionado e o sistema passa a trabalhar com as condições citadas na seção 3.3.

O fluxograma do algoritmo implementado é mostrado na Figura 4. 


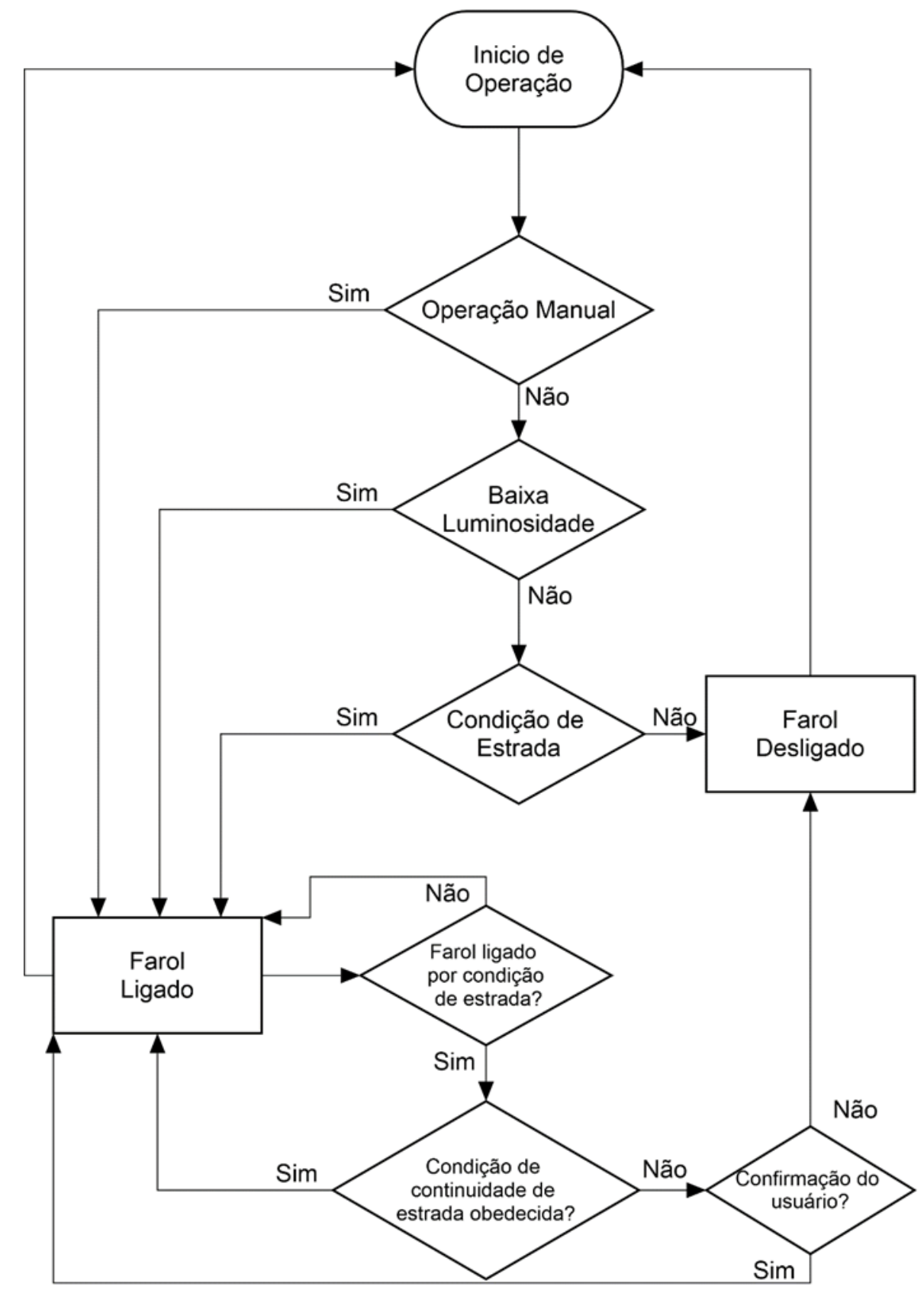

Figura 4 - Fluxograma do algoritmo de acionamento de faróis automático Fonte: Elaborado pelo autor.

\section{CONCLUSÃO}

O presente trabalho teve como objetivo apresentar um algoritmo de acionamento de faróis em rodovias por meio do uso de informações presentes no barramento do veículo de tal modo a não acrescentar custos excessivos em uma futura implementação do sistema. Esse modelo possui certo ineditismo, visto que não existem trabalhos semelhantes na literatura, até 
mesmo pela ausência de necessidade de acendimento dos faróis durante o dia até a aprovação da Lei 13.290/2016.

O desenvolvimento do modelo enfrentou o desafio da falta de dados disponíveis por parte das montadoras, no caso específico de velocidade, giro do motor, angulação do volante, entre outros, em diferentes tipos de ambientes, como rodovia e cidade. Para contornar tal empecilho, foram realizadas estimativas estatísticas das características de diferentes tipos de rodovias, de tal modo a se inferir o comportamento dessas variáveis e estimar os parâmetros que deram contorno às condições do algoritmo.

Observou-se que tal sistema tem potencial de se tornar aplicável comercialmente, haja vista a necessidade iminente da indústria por tecnologias de reconhecimento de rodovias para o acendimento automático e inteligente de faróis. Esse tipo de sistema de detecção também teria outras aplicações, como controle de estabilidade inteligente em caso de operação em rodovias.

Contudo, o sistema precisa ser melhor calibrado por meio de dados reais de veículos em diferentes situações, dados estes que as montadoras e desenvolvedoras de componentes possuem. Essa calibração com dados reais serviria para ajustes finos nos parâmetros de contorno do sistema e, consequentemente, garantiria uma confiabilidade maior ao modelo proposto.

\section{ALGORITHM OF INTELLIGENT ACTIVATION OF AUTOMOTIVE HEADLIGHT ABSTRACT}

The Law 13.290/2016 made it compulsory for vehicles to use low headlights on highways during the day, in order to reduce the number of accidents, especially considering the frontal collision on two-way roads and accidents involving pedestrians and cyclists. Several European countries, Canada and some states of The U.S have adopted similar measures. Before such a scenario, a new demand arises in the automotive industry. A system that will trigger the headlight if the vehicle travels on highways and also will turn it off, if it traffics on urban roads, in an automatic and intelligent way. Therefore, the purpose of this paper is, through information already available in the vehicle, i.e., without the need for major investments by carmakers, propose an automatic activation algorithm of the headlights when the vehicle traffics on highways, i.e., an intelligent system. A study of the peculiar characteristics to each kind of road (highways and urban roads) will be conducted, as well an evaluation of which variables will be used in order to determine if the vehicle traffics on a highway or not, by means of statistical analysis.

Keywords: Automotive systems. Automotive electronics. Embedded systems. 


\section{REFERÊNCIAS}

FRANZ, C. M.; VIEIRA, J. R. S. A história do trânsito e sua evolução. [S.l: s.n.], 2012.

MENDES, R. F. O Código de Trânsito brasileiro e a obrigatoriedade do air bag e do ABS. Âmbito Jurídico, v. XII, 2009.

THE AA. Daytime running lights. Disponível em: <http://www.theaa.com/motoring_advice/ safety/daytime-running-lights.html>. Acesso em: 12 set. 2016.

\section{DADOS DOS AUTORES}

\section{Andrey Gustavo de Souza}

Lattes: http://lattes.cnpq.br/6925274649478021

E-mail: andrey.souza@posgrad.ufla.br

Mestrando em Engenharia de Sistemas pela Universidade Federal de Lavras (UFLA). Graduado em Engenharia Elétrica pelo Instituto Federal Minas Gerais - Campus Formiga.

\section{Gustavo Lobato Campos}

Lattes: http://lattes.cnpq.br/9613750934178733

E-mail: gustavo.lobato@ifmg.edu.br

Doutor em Ciências Técnicas Nucleares pela Universidade Federal de Minas Gerais (UFMG). Mestre em Engenharia Elétrica pela Pontifícia Universidade Católica de Minas Gerais (PUC Minas). Graduado em Engenharia Eletrônica e de Telecomunicação pela PUC - Minas. Atualmente é professor efetivo do Instituto Federal Minas Gerais - Campus Formiga. 